\title{
IMPACTOS DA URBANIZAÇÃO EM BACIAS HIDROGRÁFICAS: O CASO DA BACIA DO RIO JAGUARIBE, CIDADE DE JOÃO PESSOA/PB.
}

\author{
Impacts of development in river basins: the Jaguaribe river basin case, João Pessoa/PB.
}

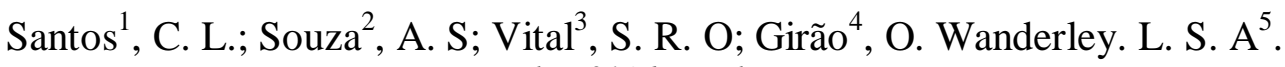

caiolima21@hotmail.com;

\begin{abstract}
Resumo
Este trabalho tem por finalidade analisar os principais impactos causados pelo processo de urbanização observados na bacia hidrográfica do rio Jaguaribe, município de João Pessoa, estado da Paraíba, Nordeste do Brasil. Para tanto, realizou-se a caracterização dos processos, bem como a descrição dos fatores geradores que incidem diretamente na integridade física do rio Jaguaribe dando origem a ambientes de forte suscetibilidade ambiental. Na área estudada observamse diversas intervenções mal planejadas, acompanhadas de ações como remoção da mata ciliar, ocupação das margens e aterros. Desta feita, observada a condição atual da área em questão, faz-se necessário adotar de medidas técnicas e educativas com vistas à mitigação dos impactos, além da preservação e revitalização da área.
\end{abstract}

Palavras-chave: Impactos da Urbanização, Bacias hidrográficas urbanas, Rio Jaguaribe.

\begin{abstract}
This study aims to analyze the main impacts caused by the urbanization process observed in the basin of the Jaguaribe river, João Pessoa, Paraíba State, Northeast Brazil. In order to do that, studies of the characterization of processes were necessary to be done, as well as the description of the factors that generate a direct impact on the physical integrity of the Jaguaribe river giving rise to strong environmental susceptibility environments. In the area in which the study was done, several poorly planned interventions were observed such as removal of riparian vegetation, the banks occupation and landfills. Therefore, observing the current condition of the area in question, it is necessary to adopt technical and educational measures aimed at mitigating the impacts, as well as preservation and revitalization of the area.
\end{abstract}

Keywords: Impacts of Urbanization, Urban Watersheds, Jaguaribe river.

\section{INTRODUÇÃ̃O}

As cidades correspondem a um ambiente de predomínio dos elementos humanos sobre os elementos naturais, que se encontram, sobremaneira, em situação adversa, em diferentes níveis de alteração em relação a sua forma e dinâmica natural. Essas transformações podem atingir de modo direto ou indireto o cotidiano das pessoas que residem nos espaços urbanos, resultando em diversos problemas para a dinâmica do ambiente natural, para a infraestrutura das cidades e para a saúde da população urbana.

\footnotetext{
${ }^{1}$ Caio Lima dos Santos, Doutorando do Programa de Pós-Graduação em Geografia - UFPE, Recife-PE/Brasil.

${ }^{2}$ Alexandre dos Santos Souza, Doutorando do Programa de Pós-Graduação em Geografia-UFPB, João Pessoa-PB/Brasil.

${ }^{3}$ Saulo Roberto de Oliveira Vital, Professor Adjunto - Departamento de Geografia-UFRN, Caicó-RN/Brasil.

${ }^{4}$ Osvaldo Girão da Silva, Professor Adjunto - Departamento de Geografia - UFPE, Recife-PE/Brasil.

${ }^{5}$ Lucas Suassuna de Albuquerque Wanderlei, Programa de Pós-Graduação em Geografia-UFPE, Recife-PE/Brasil.
} 
A ocupação do espaço urbano tem se realizado, em geral, de modo desorganizado, sem a tomada de precauções que visem a prevenção de danos ao meio ambiente, sendo esse o principal fator de transformação das características naturais dos elementos físicos presentes nesses espaços. Essa situação tem se refletido diretamente no cotidiano das pessoas, não sendo raro vincular-se aos meios de comunicação, com notícias relacionadas à ocorrência de desastres naturais, sendo as situações de risco o principal impacto da urbanização em relação às bacias hidrográficas

Esses impactos são gerados a partir do modo como ocorre o uso e ocupação da terra, desconsiderando, quase sempre, a dinâmica do meio físico, resultando na geração de riscos, quando da ocorrência de movimentos de massa, processos erosivos, enchentes, inundações e alagamentos.

Desse modo, o presente trabalho pautou sua análise nos principais impactos causados pelo processo de urbanização observados na bacia hidrográfica do rio Jaguaribe, município de João Pessoa-PB, tendo como objetivo a caracterização desses processos e a descrição dos fatores geradores.

\subsection{Localização da área de estudo}

A área em estudo corresponde a uma bacia hidrográfica totalmente inserida numa zona urbana, desde sua nascente até sua desembocadura, cortando João Pessoa, capital do estado da Paraíba na direção W/E (Figura 1). Cabe destacar que, apesar de representar o principal rio urbano da cidade, e também contemplar uma área de preservação permanente de aproximadamente 517,80 ha, a região apresenta porções com acentuada descaracterização de seus atributos naturais, o que resulta na formação de fortes impactos decorrentes da urbanização.

Nessa perspectiva, observa-se na referida bacia que, apesar do predomínio urbano, é importante destacar a presença de uma reserva de mata atlântica, denominada "Mata do Buraquinho", em seu interior. Tal característica natural, não minimiza as alterações decorrentes de agressões antrópicas que tem impactado de forma negativa a área de estudo. 


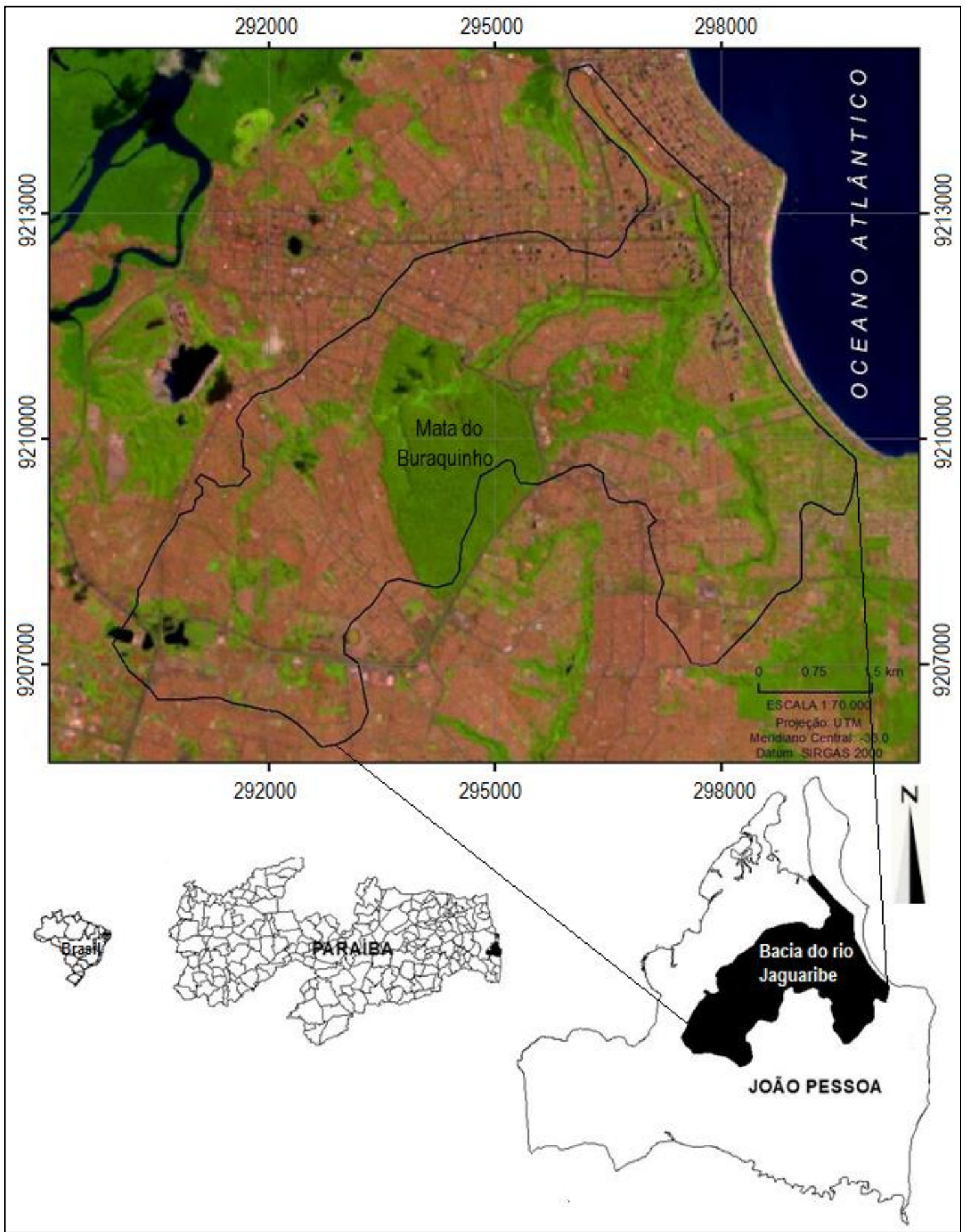

Figura 1. Localização da bacia do rio Jaguaribe, João Pessoa/PB.

\section{METODOLOGIA}

\subsection{Desenvolvimento teórico-metodológico}

Para compreender os fenômenos e os impactos ambientais ocorridos em bacias hidrográficas presentes em perímetros urbanos, Jesus (2004) classifica os cortes, aterros, erosão e assoreamento 
como feições do modelado antrópico resultantes do processo de urbanização como fatores potenciais de risco geomorfológico, sendo estes, responsáveis por deslizamentos e inundações.

Para Rodrigues e Moroz-Caccia Gouveia (2013), os principais impactos ambientais decorrentes do processo de urbanização são: os movimentos de massa, corridas e enxurradas, degradação e esgotamento de recursos hídricos, inundações, contaminação do solo por disposição de rejeito, aumento das taxas de erosão, assoreamento, recalques, colapsos do solo, dentre outros.

O comportamento do escoamento superficial direto sofre alterações significativas em decorrência do processo de urbanização em uma bacia hidrográfica, principalmente como consequência da impermeabilização da superfície dos interflúvios, o que gera maiores picos e vazões. Para Bledsoe e Watson (2001), mesmo em baixos índices, a impermeabilização do solo tem o potencial de alterar a dinâmica de um canal fluvial. Para esses autores, a gestão de uma bacia hidrográfica deve ser baseada na compreensão dos possíveis impactos causados pela mudança no uso da terra e na identificação dos canais mais susceptíveis as alterações na dinâmica do escoamento superficial.

O processo de impermeabilização do solo resulta também no aumento da vazão do rio, pois promove um aumento significativo na disponibilidade de água no canal, principalmente em situação de extrema pluviosidade, o que irá promover um maior processo erosivo das margens. A montante, a situação descrita acima, resulta na formação de processos erosivos mais acentuados nas margens, chegando, em diversos casos a ocasionar movimentos de massa (GREGORY, 2006).

A formação de um núcleo urbano em um ambiente fluvial irá influenciar diretamente na dinâmica natural da bacia hidrográfica. Um dos primeiros reflexos será no aumento do escoamento superficial, pois, por conta da impermeabilização do solo, ocorrerá uma menor ou nenhuma infiltração da água das chuvas, o que promove um maior poder erosivo sobre as áreas de solo exposto, e ocasionará o assoreamento do canal. Uma vez que o canal se encontra assoreado, a sua capacidade de armazenamento diminui e, estando essa situação associada ao aumento do escoamento superficial, o canal fluvial estará mais suscetível a ocorrência de enchentes e inundações.

Tundisi e Tundisi (2011) apresentam os principais problemas decorrentes da urbanização que incidem sobre os recursos hídricos. Os autores compreendem que o escoamento superficial sofre significativas alterações no processo de urbanização de uma bacia hidrográfica, como consequência do processo de impermeabilização do solo.

Guerra e Marçal (2012) afirmam que o rápido crescimento das cidades causa significativa pressão sobre o meio físico, ocasionando diversos problemas, tais como a poluição atmosférica, poluição do solo e corpos hídricos, deslizamentos, enchentes, dentre outros. Os referidos autores 
compreendem que à medida que o ambiente urbano é transformado pela ação antrópica, ocorre uma série de respostas geomorfológicas, representadas com maior evidência pelos movimentos de massa e enchentes.

$\mathrm{Na}$ maioria dos casos, a formação de uma área urbana em um ambiente fluvial resulta na alteração do canal, principalmente pela ação erosiva das margens e pelo processo de assoreamento, mas, sobretudo, quando há uma ação do poder público no intuito de solucionar esses problemas, representada na maioria das vezes pela retificação e pela dragagem do canal. Essa ação prioriza a diminuição de ocorrência de enchentes e alagamentos, porém, acentua o processo de erosão das margens e do leito fluvial, por ocasião do aumento da velocidade do fluxo (GREGORY, 2006).

Simon e Cunha (2008) assinalam que as principais transformações geomorfológicas oriundas da intervenção antrópica que ocorreram na bacia hidrográfica de Santa Bárbara, município de Pelotas/RS, são representadas por: construção de aterros, com o objetivo de corrigir irregularidades topográficas e manter a área ocupada acima do nível de alagamento; construção de canais (na planície de inundação) receptores da drenagem de outras áreas (médio e alto curso fluvial); retificação de canais em áreas de ocupação desordenada; e canalização de cursos d'água que captam drenagens direcionadas para um reservatório dentro da bacia, além do processo impermeabilização do solo com a expansão urbana. Esses aspectos contribuem para que haja um reajuste nos processos, causando desequilíbrios morfodinâmicos.

\subsection{Procedimentos técnicos}

Para desenvolvimento deste trabalho foi adotada a linha metodológica proposta por Libault (1971), o qual definiu os seguintes níveis de análise:

- Compilatório: coleta e compilação de dados pertinentes à pesquisa, neste caso, imagens de satélite, registros fotográficos e mapas.

- Correlatório: etapa de comparações das informações, visando estabelecer correlações significativas ao desenvolvimento do trabalho.

- Semântico: etapa onde as verificações anteriores passam por um processo de transformação que favorecem a tomada de decisões lógicas.

- Normativo: quando os resultados são demonstrados em forma de modelos da realidade, de planejamento, caracterização ambiental, entre outros.

Seguindo estes procedimentos, num primeiro momento, foi realizado o levantamento bibliográfico e de produtos cartográficos (imagens de satélite e cartas topográficas), necessários para caracterização e delimitação da área de estudos. A observação dos fenômenos estudados na 
área foi realizada através de verificação in loco e de fotografias disponibilizadas pela Defesa civil do município de João Pessoa.

A delimitação da bacia hidrográfica do rio Jaguaribe foi realizada de modo automático no software Global Mapper 15, com base na vetorização de curvas de nível das folhas I-11, I-12, J-11, J-12 e K-11, de escala 1:10.000, com equidistância de 5 metros entre as curvas de nível, do convênio entre o INCRA/ESTADO DA PARAÍBA/SEDENE. A vetorização se deu em ambiente SIG (Sistema de Informações Geográficas). As correções das distorções geradas na delimitação automática foram realizadas manualmente no software Arcgis 10.2, tomando por base a disposição das curvas de nível nas cartas topográficas.

Os trabalhos de campo ocorreram entre os meses de fevereiro e outubro de 2015, e tiveram como objetivo analisar o principal impacto na bacia hidrográfica do rio Jaguaribe decorrente do processo de urbanização. Desse modo, foram realizadas três visitas de campo, ao longo do baixo, médio e alto curso do rio Jaguaribe. Os procedimentos adotados nessas atividades consistiram basicamente em fotografar e descrever as áreas observadas.

\section{RESULTADOS E DISCUSSÃO}

Os principais impactos decorrentes do processo de urbanização observados na bacia hidrográfica do rio Jaguaribe, são: enchentes e inundações (Figura 2); processos erosivos acentuados (Figura 3), que por vezes provocam deslocamento de detritos em encostas e o consequente assoreamento dos canais fluviais; e a poluição dos corpos hídricos. Tais processos resultam da associação da dinâmica natural devido ao modo como ocorre o uso e ocupação das terras na localidade.

O processo de urbanização das áreas onde há predomínio de ocupações irregulares, se deu de modo desordenado, formadas por população de baixo poder aquisitivo, que se alocam em moradias precárias, principalmente às margens do rio Jaguaribe e nas extensões das vertentes e dos interflúvios da bacia. Nessa perspectiva, observasse que os moradores dessas áreas têm recorrido, em muitos casos, ao uso de fossas negras ou mesmo à canalização de efluentes domésticos diretamente no leito do canal fluvial, o que intensifica a suscetibilidade a processos de deslizamentos, uma vez que tal prática potencializa a formação de processos erosivos, tais como as ravinas, sulcos e voçorocas. 


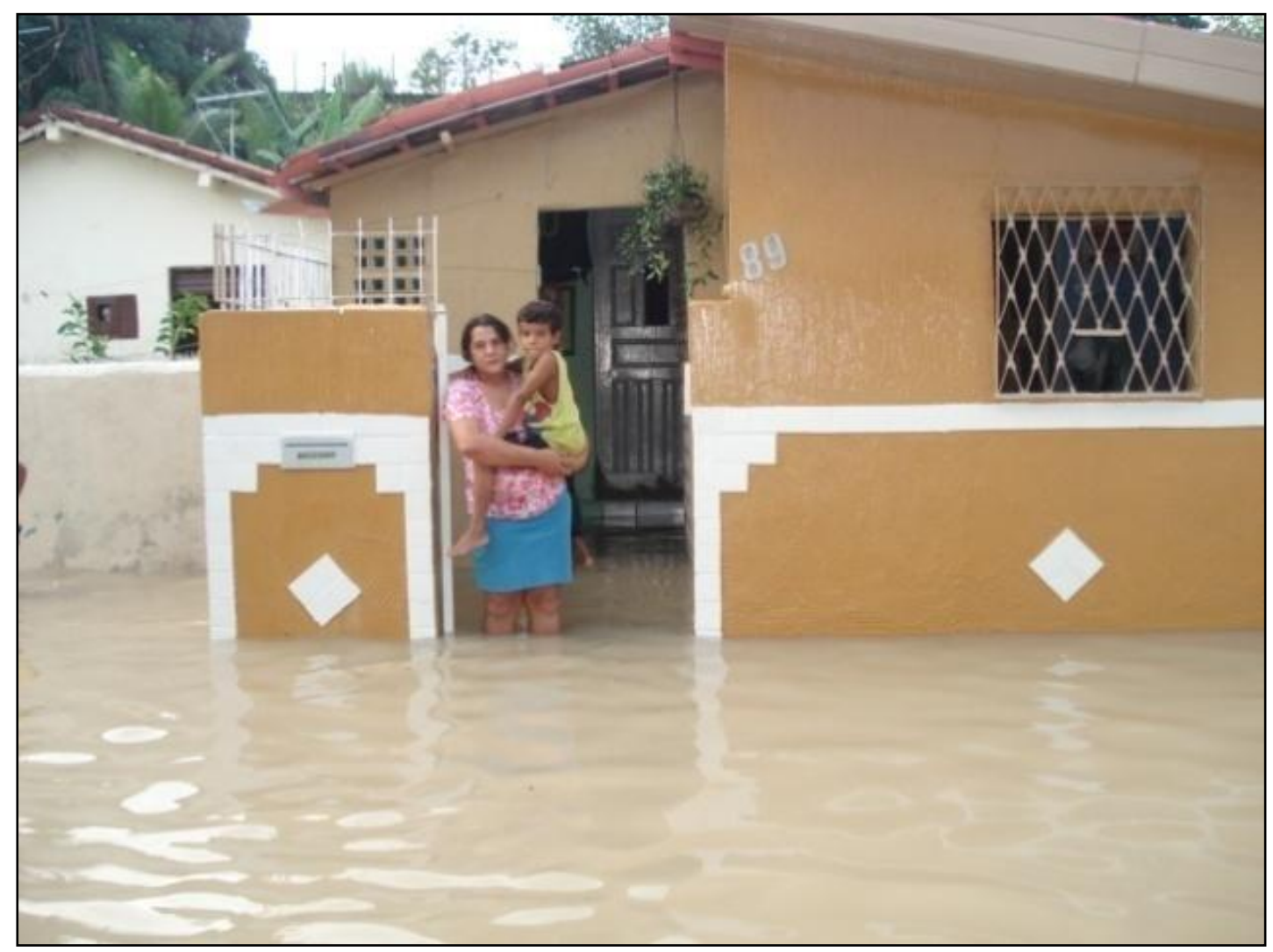

Figura 2. Enchentes na comunidade Tito Silva, ocorrida no ano de 2013. Fonte: Defesa Civil de João Pessoa.

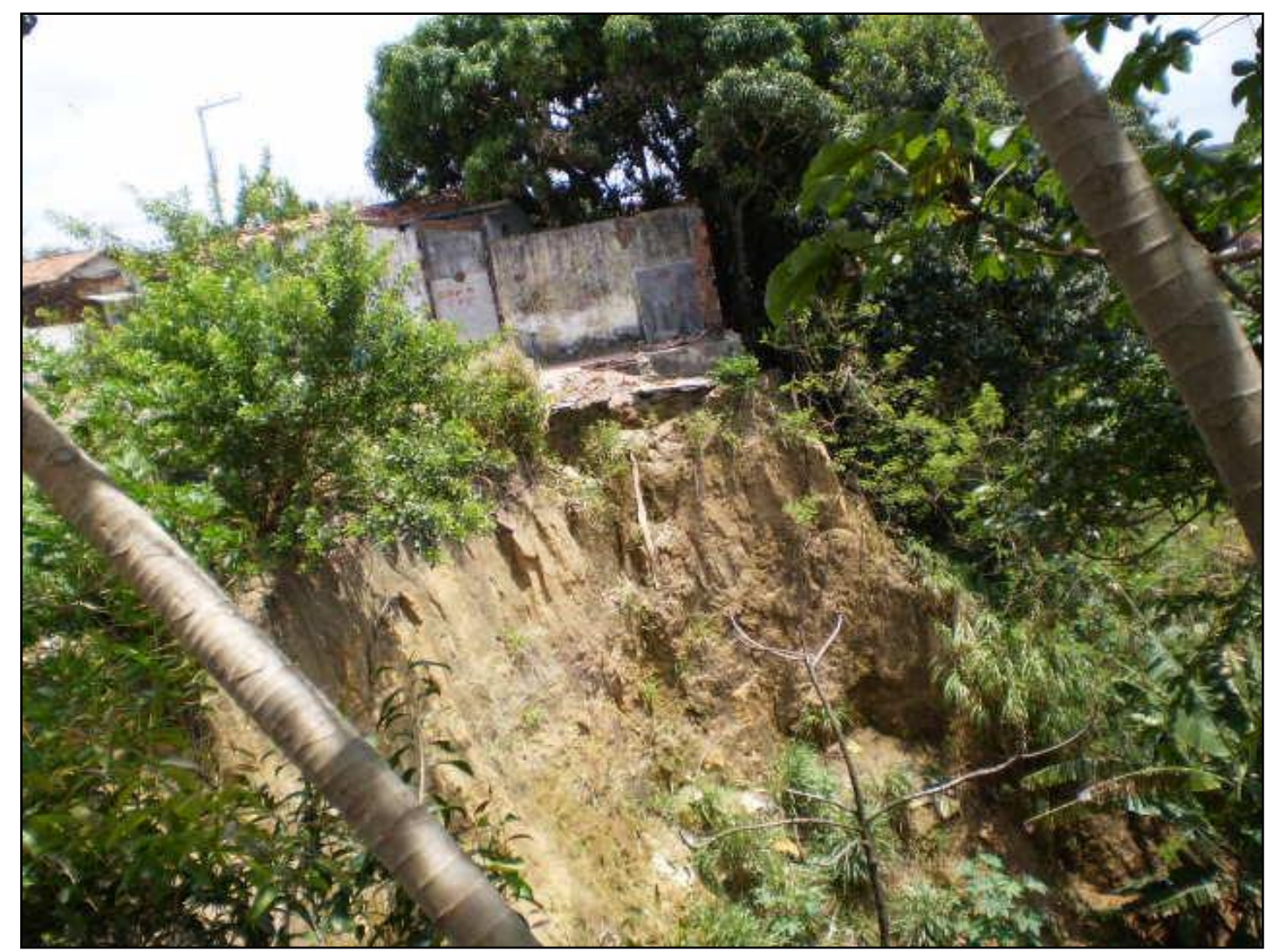

Figura 3. Processo erosivo acentuado em encosta na Comunidade do Timbó. Fonte: Defesa Civil de João Pessoa. 
As áreas onde a população residente desfruta de melhor poder aquisitivo, são caracterizadas por forte processo de impermeabilização do solo. Tais áreas estão localizadas, em sua maioria, no contexto dos tabuleiros costeiros, que por sua vez, apresentam forma plana e tabular, suavemente ondulados e pouco dissecados. O aspecto físico que caracteriza a área, associado ao modo como ocorre o uso e ocupação das terras, potencializa o escoamento superficial, ocasionando a gênese de problemas, como a erosão das vertentes e o consequente assoreamento do canal fluvial, além de provocar o aumento dos picos de cheias, no momento de maior total pluviométrico.

A poluição das águas, nessa bacia, configura uma zona de extrema vulnerabilidade, tanto para comunidades ribeirinhas que ocupam suas margens, quanto para a biota. A poluição gera nessa região vetores de doenças, agrava a qualidade de vida humana e afeta os organismos vivos que habitam essas águas, além degradar a vegetação natural, fato observado na proliferação das plantas anaeróbicas em toda leito do rio Jaguaribe, que apresenta em toda sua extensão diversas áreas que se encontram totalmente coberta por essas plantas, contribuindo para a desoxigenação do rio (Figura 4).

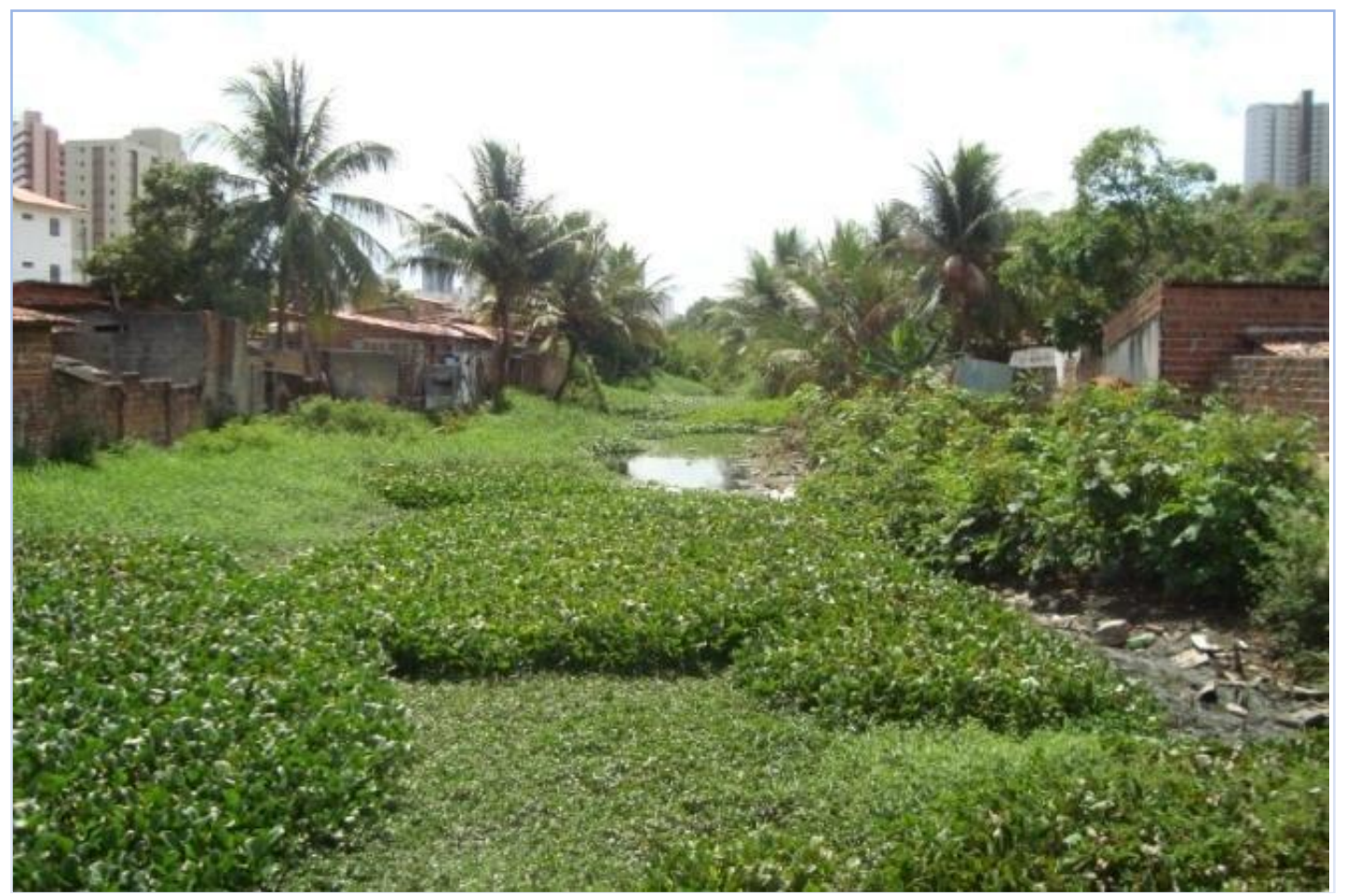

Figura 4. Canal fluvial fortemente eutrofizado e poluído pela deposição de resíduos. Fonte: Defesa Civil de João Pessoa.

A outra forma de poluição que afeta não só o rio, mas as comunidades que ocupam a área, sendo prejudicial a todos, é a deposição de lixo ao seu redor ou até em suas águas. A limpeza urbana (deposição e coleta) do lixo nas áreas das margens do rio e nas comunidades é precária, 
apresentando um impacto ambiental direto, não só ao rio, mas também as comunidades que são diariamente atingidas por diversos tipos de doenças.

Outro fator agravante na área da bacia do rio Jaguaribe é o exponencial crescimento urbano da cidade de João Pessoa, que desde o início desconsiderou as características físicas do ambiente em questão. A cidade se expandiu ocupando as nascentes, interflúvios, encostas e vales, sobre os quais não foram aplicadas políticas públicas de uso, conservação e ocupação adequada, fato que afetou diretamente a qualidade do ambiente por necessidades socioeconômicas.

\section{CONSIDERAÇÕES FINAIS}

Os impactos ambientais provocados pelo processo de urbanização observados na bacia do rio Jaguaribe decorrem da forma como ocorre a urbanização. Desse modo, admitindo-se a complexidade, custos e benefícios socioambientais que podem ser alcançados numa perspectiva de sustentabilidade ambiental, consideramos ser imprescindível:

- Definir o zoneamento do perfil sanitário da bacia do rio Jaguaribe observando os pontos críticos nos quais é mais intenso o transporte de resíduos pelo escoamento fluvial e presença de redes clandestinas de esgoto;

- Revitalização integral da mata ciliar e drenagem longitudinal periódicas do rio até que seja observada uma vazão compatível com um padrão aproximando ao natural;

- Estabelecimento de políticas públicas e de educação ambiental, não apenas com as comunidades ribeirinhas, mas com toda população urbana que ocupa a bacia.

Evidentemente, tais medidas demandam tempo e recursos consideráveis. Todavia deve-se considerar que benefícios obtidos com a restauração dessas áreas trarão resultados vitais à qualidade de vida urbana, ou seja, na saúde das comunidades envolvidas, na diminuição de pragas urbanas, reconstituição da biota e da paisagem, e finalmente na valorização econômica da qualidade de vida e do espaço.

\section{REFERÊNCIAS}

BLEDSOE, B. P.; WATSON, C. C.; EFFECTS OF URBANIZATION ON CHANNEL INSTABILITY. Journal of the American water resources association, v. 37, n. 2, p. 255-270, 2001.

GREGORY, K. J. The human role in changing river channels. Geomorphology, v. 79, p. 172-191. 2006. 
GUERRA, A. J. T.; MARÇAL, M. S. Geomorfologia Ambiental. Rio de Janeiro: Bertrand Brasil, 2012.

JESUS, A. S. Geomorfologia antrópica, riscos geomorfológicos e hidrológicos na porção centroleste de Anápolis (GO). Boletim Goiano de Geografia, v. 24, n. 1-2, 2004.

LIBAULT, A. Os quatro níveis da pesquisa geográfica. Métodos em Questão, São Paulo: Instituto de Geografia (USP), n. 1, p. 1-14, 1971.

RODRIGUES, C.; MOROZ-CACCIA GOOUVEIA, I. C. Importância do fator antrópico na redefinição de processos geomorfológicos e riscos associados em áreas urbanizadas do meio tropical úmido. Exemplos na Grande São Paulo. In: GUERRA, A. J. T.; JORGE, M. C. O. (Org.). Processos erosivos e recuperação de áreas degradadas. São Paulo: Oficina de textos, 2013.

SIMON, A. L. H. CUNHA, C. M. M. L. Alterações geomorfológicas derivadas da intervenção de atividades antrópicas: análise temporal na Bacia do Arroio Santa Bárbara - Pelotas (RS). Revista Brasileira de Geomorfologia, v. 9, n. 2, p. 29-38, 2008.

TUNDISI, J. G.; TUNDISI, T. M. Recursos hídricos no século XXI. São Paulo: Oficina de Textos, 2011.

Recebido em: 14/08/2016

Aceito para publicação em: 01/10/2016 